\title{
Influence of parental anxiety on children's behaviour during their visits to dental clinic: a short clinical study
}

\author{
Lakshmi Thribhuvanan* ${ }^{*}$, M. S. Saravanakumar and G. Anjana
}

\begin{abstract}
Background: Anxiety and fear of dental treatment in children have been recognized as sources of serious health problems. Parents are known to subtly transmit feelings of fear and anxiety to their children Commonly which has influence on children's dental anxiety are maintenance of general health of the child, past dental history, oral hygiene practices and attitudes in the family towards oral health and high dental anxiety of parents, all of these contributed to sustained and elevated levels of children's dental anxiety.

Aim: This study was undertaken to evaluate the influence of parental anxiety on their children during their visit to dental clinics.

Objective: To determine the relationship between parental anxiety level and that of a child.

Methods: A short clinical study was performed to assess the influence of parental anxiety on their children during their visit to dental clinics. Twenty subjects were randomly selected and their parents were given the Modified Dental Anxiety Scale Questionnaire (MDAS) and their physiologic parameters were measured during each visit. Similarly, the children's responses were analyzed using the Facial Image Scale (FIS) and their physiologic parameters were measured.
\end{abstract}

Results: The values show a positive correlation $(P<0.05)$ between the scores (MDAS and FIS) and physiologic parameters (blood pressure and heart rate) of parents and their children.

Conclusion: The dental anxiety levels in parents influence the anxiety levels in children.

Keywords: Parental anxiety, Facial Imaging Scale, Modified Dental Anxiety Scale

\section{Background}

Dental anxiety is defined as an abnormal fear of visiting the dentist for preventive care or therapy and unwarranted anxiety over dental procedures (McNeil et al. 2011). The reported incidence and prevalence of unavoidable dental anxiety in children during their visits to dental operatory is found to be in the range of $5-33 \%$ (Chhabra et al. 2012). Dental fear and behavior are likely to have multifactorial origins which can be broadly classified into

\footnotetext{
*Correspondence: lakshmithribhuvanan91@gmail.com Department of Pedodontics and Preventive Dentistry, Royal Dental College, Iron Hills, Chalissery, Palakkad, Kerala 679536, India
}

personal, environmental, or situational factors (Chhabra et al. 2012). Knowledge on the origin of dental fear and uncooperative behavior in a child patient thus help the pediatric dentist to plan appropriate behavior management and treatment strategies (Berge et al. 2001). This prevalence of childhood dental anxiety have shown to have detrimental effects on child's quality of life spanning from short term health hazards such as persistant avoidance of receiving dental care thereby increasing the incidence of caries and profounding prevalence of untreated dental infections. The long term health effects include that these children exhibiting such severe dental anxiety refrains from being a cooperative dental patient as an 
adult, an adult who neglects his dental hygiene and status or an adult who consistently avoids being treated by the dentist inspite of suffering unwanted side effects of dental decay thus resulting in individuals quality of life both personally and socially (Coxon et al. 2019). Identifying anxiety in children at the earliest possible age is essential and helpful to select methods of behaviour management. Dental anxiety possess a multifactorial etiology. Commonly associated factors which has an undoubtful influence on children's dental anxiety are socioeconomic status of the family, maintenance of general health and wellbeing of the child, past dental history, oral hygience practices and attitudes sustaining in the family towards oral health and high dental anxiety of parents, all of these contributed to sustained and elevated levels of children's dental anxiety (Soares et al. 2020).

Both dental anxiety and fear evoke physical, cognitive, emotional, and behavioral responses in an individual which is a frequently encountered problem in dental offices (Soares et al. 2020). Parent's dental fear, especially the mother's, has been shown to have a significant impact on children's dental fear and behavior (Soares et al. 2020). Parents play an important role in ascertaining the dental behavior of a child patient, and it is for this reason that the role of the parent in dental fear always remains as a topic of interest to pediatric dentists (D'Alessandro et al. 2015). Presence of parents might be active or passive during dental treatment Involvement of parents as a passive yet silent helper can provide a calm and relaxing environment without unnecessary interference during dental treatment. Adequate parental education and awareness regarding the beneficial aspects of receiving dental treatment, as well as their recommended active participation will act as an adjunct in establishing good rapport between the child and the dentist (Afshar et al. 2011).

Evidence-supported techniques such as Tell Show Do, distraction techniques should be adapted to meet the needs and aid in effective communication with dentally anxious children. However, delivery of these interventions needs to be financially available to every patient which can be carried out in a cost effective way in routine dental practice. All available members of dental profession must be aware of child's and parents perceptions of dental fear and anxiety and their attitude towards receiving dental treatment in order to meet their advisable needs and provide quality care in an effective manner that is comforting and reduces anxiety of both the parents as well as the child. Evaluating a child's level of dental fear and anxiety before commencing the actual dental treatment can thus help in reducing the associated behavior management problems (Afshar et al. 2011). Efforts should therefore continue to be directed towards the development and validation of suitable instruments for the detection of dental anxiety in children. In light of multifactorial origins, pediatric dental fear and anxiety can be well prevented and intercepted through controlled and coordinated efforts of dentists, dental auxiliaries, pediatric patients, and their parents respectively during the treatment procedures. A well designed adaptation of combined behaviour management techniques and approaches before, during, and after the dental visit will contribute to a pleasant dental environment to the child. Prompt and successful management of dental fear and anxiety paves the road to satisfactory clinical outcome and better oral health, apart from this it also instills confidence and positive attitude in pediatric patients towards receiving dental treatment thereby creating and instilling an enlightening positive approach (Farhat-McHayleh et al. 2009).

\section{Aim of the study}

To evaluate the influence of parental anxiety on their children during their visit to dental clinics.

\section{Objective of the study}

To determine the relationship between parental anxiety level and that of the child patient.

To determine the physiological variations in children and parents during their initial visit and how it changes in subsequent visits.

\section{Methodology}

The present study was conducted at the Department of Pedodontics and Preventive Dentistry, Palakkad, Kerala, India.

\section{Selection of cases inclusion criteria}

- Children both male and female of 6-12 years of age.

- Children visiting the dentist for the first time.

- Children visiting the department with their parents.

- Children with definite indications of oral prophylaxis, restorations, and extractions thereby necessitating a minimum of two dental visits.

\section{Exclusion criteria}

- Children with a known congenital anomaly, developmental, and/or systemic disorders.

- Children with a history of prolonged illness.

- Children who had a previous history of dental treatment. 


\section{Methods}

First visit

Hundred children of 6-12 years old and their accompanying parents were randomly selected from patients visiting the outpatient facility in the Department of Pedodontics and Preventive Dentistry, Palakkad, Kerala, India as per the inclusion criteria. Of these 100 children 50 were boys and 50 were girls. Depending on their age the children were considered to belong to single group of 6-12years. Hence to create a brief patient profile child's sex, age, socioeconomic status and chief complaint (Table 1) were

Table 1 Patient profile

\begin{tabular}{ll}
\hline Sex & Girls-50 \\
& Boys-50 \\
Age & $6-12$ years \\
Socioeconomic status & Lower middle class-40 \\
& Lower class-60 \\
Chief complaint & Pain-40 \\
& Swelling-20 \\
& Decay-40 \\
\hline
\end{tabular}

considered. Details of the procedure were explained to the parents and consent was obtained. All the children selected had to undergo minimum of two dental visits. These children were advised to undergo either restoration or scaling depending on their treatment needs during their subsequent visit. Initially the parents parameter namely blood pressure and heart were recorded by using sphygmomanometer and pulse oximeter respectively at two instances (1) Prior to child's oral examination, (2) After child's oral examination and they were subsequently given MDAS (Fig. 1) score cards to mark their responses in their first visit with their child to the dental clinic (Figs. 2, 3). Similarly the child's responses were recorded by measuring their blood pressure and heart rate by sphygmomanometer and pulse oximeter at two instances (1) Prior to child's oral examination, (2) After child's oral examination. Following which the children were given FIS score cards to record their responses on their first visit to dental clinic (Figs. 4, 5). From the above children, 40 were decided to undergo extraction procedure due to grossly decayed unrestorable primary teeth,

CAN YOU TELL US HOW ANXIOUS YOU GET, IF AT ALL, WITH YOUR DENTAL VISIT ? PLEASE INDICATE BY INSERTING ' $X$ ' IN THE APPROPRIATE BOX

1. If you went to your Dentist for TREATMENT TOMORROW, how would you feel ?

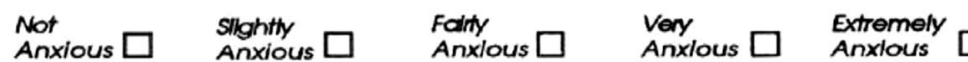

2. If you were sitting In the WAITING ROOM (walting for treatment), how would you feel ? Not Slightly $\square$ Folity Very $\square$ Extremely Anxlous $\square \quad$ Anxlous $\square \quad$ Anxlous $\square \quad$ Anxlous $\square \quad$ Anxious

3. If you were about to have a TOOTH DRILLED, how would you feel ?

Not
Anxious $\quad \begin{aligned} & \text { Sllghtly } \\ & \text { Anxious }\end{aligned} \quad \begin{aligned} & \text { Fainty } \\ & \text { Anxious }\end{aligned} \quad \begin{aligned} & \text { Very } \\ & \text { Anxious }\end{aligned} \quad \begin{aligned} & \text { Extremely } \\ & \text { Anxlous }\end{aligned} \square$

4. If you were about to have your TEETH SCALED AND POLISHED, how would you feel ?

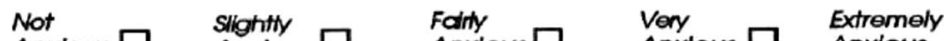
Anxlous $\square \quad$ Anxlous $\square \quad$ Anxious $\square \quad$ Anxlous $\square \quad$ Anxlous

5. If you were about to have a LOCAL ANAESTHETIC INJECTION in your gum, above an upper back tooth, how would you feel ?

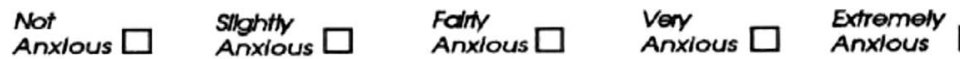

Fig. 1 Modified Dental Anxiety Scale (Farhat-McHayleh et al. 2009) 


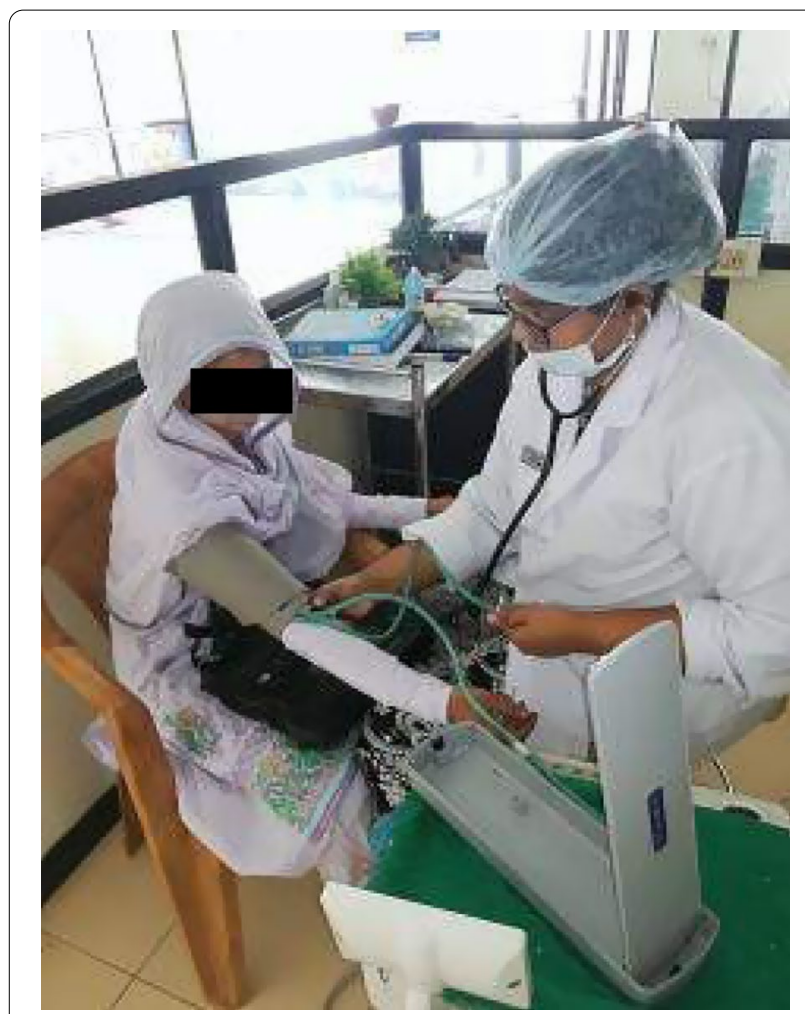

Fig. 2 Recording parent's parameter

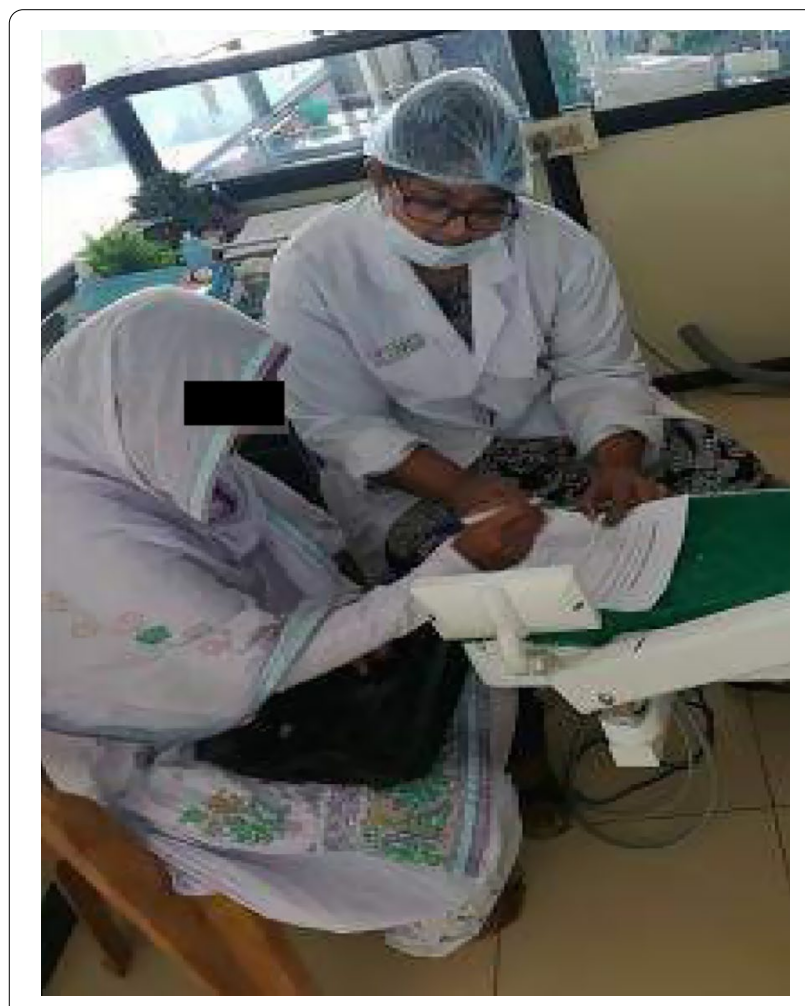

Fig.3 Parents responding to MDAS questionnaire

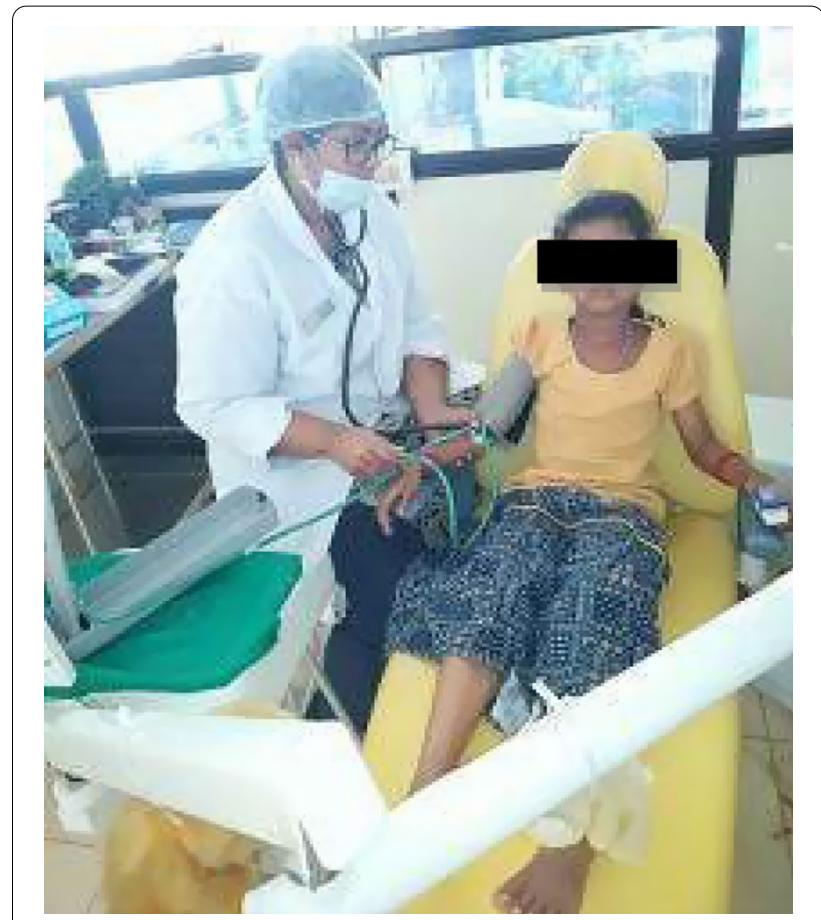

Fig. 4 Child's parameters recorded

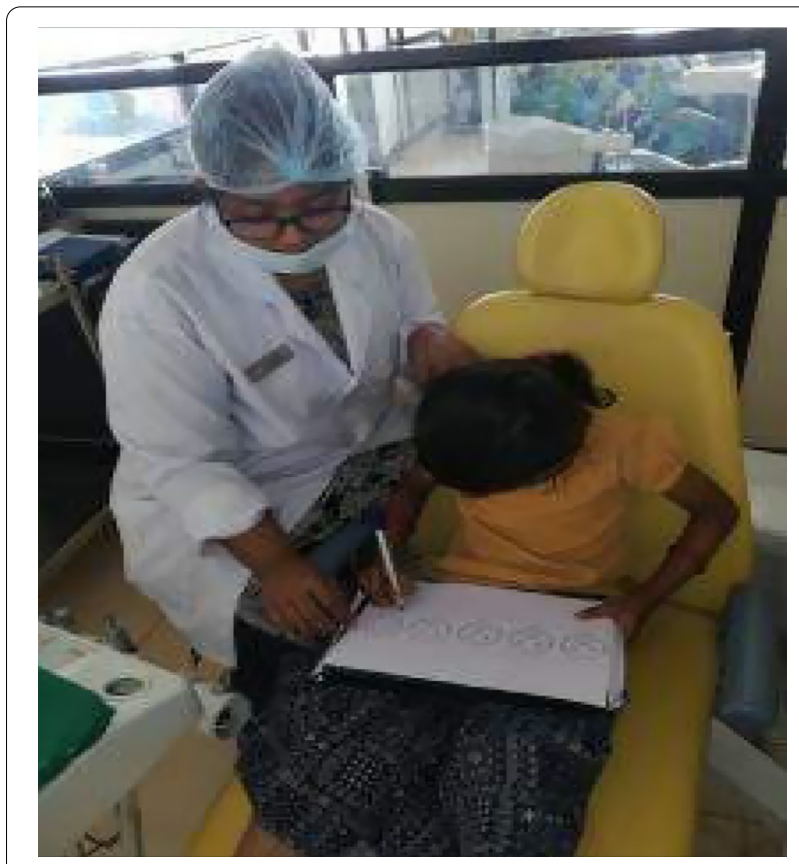

Fig. 5 Child marking responses in FIS card

40 were subjected to undergo conventional restorations and 20 of them to undergo oral prophylaxis.

The Modified Dental Anxiety Scorecard (MDAS) consists of series of five questions with options ranging 
Table 2 Interpretation of MDAS Scores (Humphris et al. 1995)

Not anxious $=1$, slightly anxious $=2$, fairly anxious $=3$, very anxious $=4$,
extremely anxious $=5$
$0-5$ (not anxious)
$6-10$ (low anxiety)
$11-14$ (moderate anxiety)
$15-18$ (high anxiety)
$19-25$ (extreme anxiety/phobic)

from "Not Anxious" to "Extremely Anxious" which is scores according from 0 to 25 (Table 2) depending on the responses. The Facial Image Scale (FIS) (Fig. 6) comprises a row of five faces ranging from very happy to very unhappy. The children were asked to point at which face they felt most like at that moment.

The scale is scored by giving a value of one to the most positive affect face and five to the most negative affect face (Table 3). Comparative evaluation of parameters of parents and children were assessed during the first visit (Table 4). Similar to the present study, many studies have used facial images to assess feelings in the pediatric patient group.

\section{Second visit}

During the second visit, the parent's vital parameters (blood pressure and heart rate) were measured before and after subjecting their children to treatment procedures by using sphygmomanometer and pulse oximeter (Table 5). The parents were then given the MDAS questionnaire to mark their responses following their child's treatment.

The children's vital parameters (blood pressure and heart rate) were measured before the treatment procedure and after treatment procedure by using a sphygmomanometer and pulse oximeter (Table 6). The children were then given the FIS scale after the completion of treatment and asked to mark their response.
Table 3 Interpretation of FIS scores (Buchanan and Niven xxxx)

$1=$ No anxiety (score 1)

$2=$ Low anxiety (score 2$)$

$3=$ Moderate anxiety (score 3 )

$4=$ High anxiety (scores 4 )

$5=$ Very high anxiety (score 5$)$

\section{Statistical analysis}

The data were entered into a computer using Statistical Package for Social Sciences (SPSS) version 22.0 (Chicago, IL, USA).Pearson's Correlation Coefficient was used to establish a correlation between the physiologic parameters (blood pressure and heart rate), along with anxiety scores of parents and children during subsequent visits to the dental clinic. A P-value equal or less than 0.05 was considered as statistically significant.

\section{Results first visit Interpretation}

Statistical Analysis was done using Pearson's Correlation coefficient which showed a positive correlation between the parameters of parents and children (Table 7). The $P$ Value is 0.001 , and the result is significant at $P<0.05$.

\section{Second visit}

Interpretation

Statistical Analysis was done using Pearson's Correlation coefficient which showed a positive correlation between the parameters of parents and children with respect to blood pressure rates and heart rate recorded during both visits. The $P$ value is 0.001 , and the result is significant at $P<0.05$. The above values depict the fact that parameters of children and parents who were subjected to extraction procedures is found to increase subsequently which highlights the fact of general fear pertaining among parents regarding extraction procedures which is gradually reflected on the child's physiologic parameters as well. There also exists subsequent correlation between FIS scores of children and MDAS
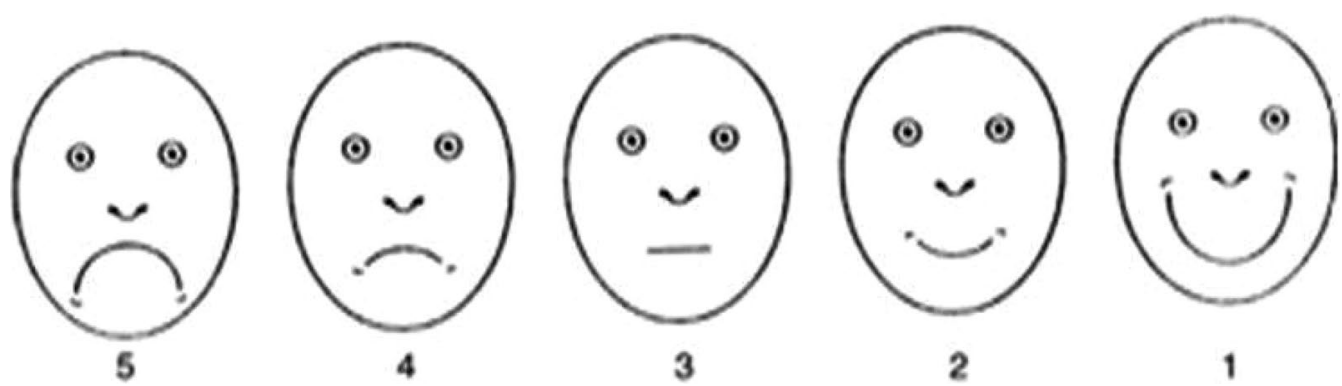

Fig. 6 Facial Image Scale Scorecard (Giri et al. 2017) 
Table 4 Comparative evaluation of parameters of parents and children during the first visit

\begin{tabular}{llllc}
\hline Parameters & $\begin{array}{l}\text { Parent's mean before child's } \\
\text { examination }\end{array}$ & $\begin{array}{l}\text { Parent's mean after child's } \\
\text { examination }\end{array}$ & $\begin{array}{l}\text { Children's mean before } \\
\text { examination }\end{array}$ & $\begin{array}{l}\text { Children's mean } \\
\text { after examination }\end{array}$ \\
\hline Systolic BP & 124 & 124 & 106 & 100 \\
Diastolic BP & 82 & 80 & 68 & 66 \\
Heart rate & 73 & 72 & 106 & 100 \\
MDAS & 11 & 11 & 3 & 2 \\
FIS & & & 3 & \\
\hline
\end{tabular}

The $P$ value is $<0.001$. The result is significant at $P<0.05$

Table 5 Comparative evaluation of parameters of parents before and after treatment procedures

\begin{tabular}{lllllll}
\hline Parameters & $\begin{array}{l}\text { Before extraction } \\
(\boldsymbol{n = 4 0 )}\end{array}$ & $\begin{array}{l}\text { After extraction } \\
(\boldsymbol{n}=\mathbf{4 0 )}\end{array}$ & $\begin{array}{l}\text { Before restoration } \\
(\boldsymbol{n}=\mathbf{4 0 )}\end{array}$ & $\begin{array}{l}\text { After restoration } \\
(\boldsymbol{n}=\mathbf{4 0})\end{array}$ & $\begin{array}{l}\text { Before scaling } \\
(\boldsymbol{n}=\mathbf{2 0})\end{array}$ & $\begin{array}{l}\text { After } \\
\mathbf{s c a l i n g} \\
(\boldsymbol{n}=\mathbf{2 0})\end{array}$ \\
\hline Systolic BP & 130 & 120 & 128 & 124 & 120 & 120 \\
Diastolic BP & 90 & 82 & 84 & 80 & 80 & 80 \\
Heart Rate & 82 & 74 & 74 & 72 & 72 & $<2$ \\
$P$ value & $<0.001$ & $<0.001$ & $<0.001$ & $<0.001$ & $<0.001$ & $<0.001$ \\
\hline
\end{tabular}

Table 6 Comparative evaluation of parameters of children before and after treatment procedures

\begin{tabular}{lllllll}
\hline Parameters & $\begin{array}{l}\text { Before extraction } \\
(\boldsymbol{n = 4 0 )}\end{array}$ & $\begin{array}{l}\text { After extraction } \\
(\boldsymbol{n}=\mathbf{4 0})\end{array}$ & $\begin{array}{l}\text { Before restoration } \\
(\boldsymbol{n}=\mathbf{4 0 )}\end{array}$ & $\begin{array}{l}\text { After restoration } \\
(\boldsymbol{n}=\mathbf{4 0})\end{array}$ & $\begin{array}{l}\text { Before scaling } \\
(\boldsymbol{n}=\mathbf{2 0})\end{array}$ & $\begin{array}{l}\text { After } \\
\mathbf{s c a l i n g} \\
(\boldsymbol{n}=\mathbf{2 0})\end{array}$ \\
\hline Systolic BP & 106 & 102 & 104 & 100 & 100 & 100 \\
Diastolic BP & 68 & 64 & 68 & 66 & 66 & 66 \\
Heart Rate & 106 & 102 & 104 & 100 & 100 & 100 \\
$P$ value & $<0.001$ & $<0.001$ & $<0.001$ & $<0.001$ & $<0.001$ & $<0.001$ \\
\hline
\end{tabular}

Table 7 Pearson's correlation coefficient evaluation of every parameters

\begin{tabular}{llll}
\hline Parameters & First dental visit $(\boldsymbol{r})$ & $\begin{array}{l}\text { Second dental } \\
\text { visit }(\boldsymbol{r})\end{array}$ \\
\hline MDAS-FSI & 0.455431 & 0.355467 & $<0.0001$ \\
Systolic P-C & 0.713987 & 0.2374981 & $<0.0001$ \\
Diastolic P-C & 0.081208 & 0.0266861 & $<0.0001$ \\
Heart rate P-C & 0.270408 & 0.194365 & $<0.0001$ \\
\hline
\end{tabular}

scores of parents depicting their acceptance of treatment level during their visits to clinics.

The Pearson's Correlation coefficient very well defines that the systolic and diastolic blood pressure as well as heart rate of child and parents were correlated in both the visits signifying that children of highly anxious parents seemed to exhibit consequently higher values simulating their parent's anxious nature during their first visit. On comparison between both the dental visits it is evidently clear that parental presence and their anxiety levels and concerns are transferred to their wards irrespective of the child's age or sex which clearly depicts the influence of parental anxiety on child's behaviour is an essential part determining the success and outcome of delivering the required dental treatment to the child. The practical applicability of the resultant correlation is that when a parents comes to the dental clinic with their child by measuring the above determined values as well as by utilizing the MDAS and FIS score cards the dentist will be able to determine the level of cooperation to be expected from the child on dental chair and accordingly the dentist will be able to devise appropriate treatment plan coupled with adequate behavior modification techniques for the child which might make the child less anxious and train the child in accepting the dental treatment without any reluctance or withdrawal from receiving the devised strategy. 


\section{Discussion}

Worldwide statistical analysis has demonstrated that between 3 and $43.4 \%$ of children exhibit dental anxiety (Alkhadra 2017). Kent stated that one of the most consistent findings in dental anxiety research is that non- anxious patients make accurate predictions of the degree of discomfort they will feel during an appointment, while anxious patients make clinically significant overproductions, that is, they expect much more pain than they subsequently experience (Folayan et al. 2004).

Venham et al. have shown that the behavior of children improves in subsequent dental visits. The age of the child is a factor having an impact on a child's anxiety level and that the cognitive ability of a child develops with increase in age and more understanding. Buchanan and Niven found that there were no significant differences in terms of gender regarding the scores that measure dental anxiety levels with FIS (Buchanan and Niven 2002). Furthermore, in a study done by Kilinç et al. it was found that there is no significant difference in relation to gender. However other factors of sex and socioeconomic status had negligible influence on anxiety levels in children as well as their parents (Kent 1985). The improvement during subsequent visits suggests that the experience gained by the child during previous visits helped the child to recognize the non-threatening aspects of the visits and to deal with stressful dental procedures (Kent 1985). There have been numerous scales in use to measure dental anxiety. In this study, we used MDAS as the study instrument. Ilguy et al. compared sensitivity, specificity, negative/positive values and reliability of the MDAS and Corah's dental anxiety scale among Turkish populations and concluded that both the scales showed acceptable levels of specificity, sensitivity, positive and negative predictive values at cutoff points (Venham et al. 1977). Shabnam Gulzar et al. conducted a study that confirmed that MDAS is a more reliable tool in measuring parental anxiety and concluded that maternal dental anxiety had a positive correlation with a child's behavior (Ilgüy et al. 2005). Perhaps the author also stated that both the parents and children can appear to be anxious irrespective of each other's knowledge depending on their inherent ability in stress management. However there also explains that the parents responses to MDAS scores determines only their anxiety level towards dental treatment and is not necessarily made aware to their child, except in instances where the parents unknowingly transfer their dental fears to their wards by mentioning their previous painful experiences which might instill a state of anxiety in the child.These findings can be correlated with the present study which depicted reliable anxiety scores of parents during each visit to the dental clinic.
Guinot Jimeno et al reported that the highest heartrate is observed during local anesthesia administration and extractions. In the present study, childen who underwent extraction procedures had inconclusively shown an increase in heart rate which corresponds with the above findings (Guinot Jimeno et al. 2014). These pulse rate increases, which indicate increases in adrenergic activity caused by anxiety, showed us that the children's anxiety levels were found to be increasing in the clinical environment with respect to the treatment modality that was carried out. The Facial Image Scale (FIS) comprises a row of five faces ranging from very happy to very unhappy. The children were asked to point at which face they felt most like at that moment. The scale is scored by giving a value of one to the most positive affect face and five to the most negative affect face. Similar to the present study, many studies have used facial images to assess feelings in the pediatric patient group. The FIS can be employed with very young children. It has been argued that a situation arises with very young children where their lack of cognitive ability means they cannot complete questionnaires; indirect behavioral measures are the only real alternative. Studies carried out by Messer et al. confirmed that the physiological changes occur in the body as a result of the stress and anxiety suffered by patients during dental procedures (Messer 1977). The authors of these studies concluded that heart rate and blood pressure can be used as reliable indicators of anxiety. In the study Messer et al. evaluated the anxiety levels in children aged 6-9 years old and its effect on subsequent dental visits, in which he concluded that there is a direct correlation between the objective measures (blood pressure and pulse rate) and subjective measures (Facial Image Scale and Venham Picture Test) during anxiety producing dental situations (Messer 1977). Though there have been several studies that had compared the various anxiety levels, no relevant studies have so far been conducted where there had been a comparative evaluation of parameters (blood pressure and heart rate) of both parents and children along with the utilization of MDAS and FIS scores. Decisions about treatment should not be based on proper dental diagnosis only. An assessment and management of the anxiety level of the parent's may be necessary to adequately manage that of the child to break the vicious cycle of anxiety that may be set up in the family regarding dental care.

\section{Recommendation}

The influence of parental anxiety on child's behavior in during dental treatment is an important factor of concern hence studies with larger population size has to be carried out. Majority of the reported studies have been done using conventional methods, hence utilization of recent technologies like three dimensional facial softwares 
should be considered. New child friendly dental fear and anxiety scales have to be developed to create a more acceptable environment to children.

\section{Conclusions}

The present study led to the conclusion that the dental anxiety levels in parents may influence the anxiety levels in children. Based on the results from the above study the dental anxiety levels in parents influence the anxiety levels of their children. Therefore, identifying anxiety levels of parents accompanying their children can help the clinician in designing the behavior management strategies for the child accordingly. All children exhibited an improvement in the levels of dental anxiety from the first dental visit to the subsequent dental visits. Therefore, with continued experience, the child's response improved, indicating desensitization to dental stress. This study shows the correlation between the normal physiologic parameters of children and parents and the applicability of MDAS and FIS scales in measuring anxiety levels accordingly.

\section{Abbreviations}

MDAS: Modified Dental Anxiety Scale; FIS: Facial Image Scale.

\section{Acknowledgements}

The authors would like to thank the principal and all other staffs of the Department Of Pedodontics and Preventive Dentistry from the participating institution for assistance to the formulation of the project.

\section{Authors' contributions}

LT, MSS and AG: concepts, design, experimental studies, definition of intellectual content, data analysis, manuscript preparation and manuscript review. LT and MSS: literature search and clinical studies, data acquisition, statistical analysis, manuscript editing. LT: Guarantor. The authors have stated that "All authors have read and approved the manuscript"

\section{Funding}

No sources of funding was received for the above study.

\section{Availability of data and materials}

All data generated or analysed during this study are included in this published article and its supplementary information files.

\section{Declarations}

\section{Ethics approval and consent to participate}

Not applicable as this was done as a non invasive methodology of examining routine patients visiting the department for treatment. The consent to participate was given by parents.

\section{Consent for publication}

Consent was obtained for publication from department and parents.

\section{Competing interests}

The authors declare that they have no competing interests.

\section{References}

Afshar H, Baradaran Nakhjavani Y, Mahmoudi-Gharaei J, Paryab M, Zadhoosh S (2011) The effect of parental presence on the 5 year-old children's anxiety and cooperative behaviour in the first and second dental visit. Iran J Pediatr 21:193-200

Alkhadra T (2017) Effect of using zooby prophy cup versus traditional prophy cup on child anxiety. Egypt Dent J 1(63):2155-2161

Buchanan H, Niven N (2002) Validation of a Facial Image Scale to assess child dental anxiety. Int J Paediatric Dentistry 12:47-52

Chhabra N, Chhabra A, Walia G (2012) Prevalence of dental anxiety and fear among five to ten year old children: a behaviour based cross sectional study. Minerva Stomatol 61:83-89

Coxon JD, Hosey MT, Newton JT (2019) The impact of dental anxiety on the oral health of children aged 5 and 8 years: a regression analysis of the child dental health survey 2013. Br Dent J 227:818-822

D'Alessandro G, Alkhamis N, Mattarozzi K, Mazzetti M, Piana G (2015) Fear of dental pain in Italian children: child personality traits and parental dental fear. J Public Health Dent 3:60-62

Farhat-McHayleh N, Harfouche A, Souaid P (2009) Techniques for managing behaviour in pediatric dentistry: comparative study of live modelling and tell-show-do based on children's heart rates during treatment. J Can Dent Assoc 75:283

Folayan MO, Idehen EE, Ojo OO (2004) The modulating effect of culture on the expression of dental anxiety in children: a literature review. Int J Paediatr Dent 14:241-245

Giri J, Pokharel PR, Gyawali R, Bhattarai B (2017) Translation and validation of modified dental anxiety scale: the Nepali Version. International scholarly research notices

Guinot Jimeno F, Mercadé Bellido M, Cuadros Fernández C, Lorente Rodríguez Al, Llopis Pérez J, Boj Quesada JR (2014) Effect of audiovisual distraction on children's behavior anxiety and pain in the dental setting. Eur J Paediatr Dent 15(3):297-302

Humphris GM, Morrison T, Lindsay SJ (1995) The modified dental anxiety scale: validation and United Kingdom norms. Commun Dent Health

Ilgüy D, Ilgüy M, Dinçer S, Bayirli G (2005) Reliability and validity of the Modified Dental Anxiety Scale in Turkish patients. J Int Med Res 33:252-259

Kent G (1985) Cognitive processes in dental anxiety. Br J Clin Psychol 24(Pt 4):259-264

McNeil DW, Helfer AJ, Weaver BD, Graves RW, Kyle BN, Davis AM (2011) Memory of pain and anxiety associated with tooth extraction. J Dent Res 90(2):220-224

Messer JG (1977) Stress in dental patients undergoing routine procedures. J Dent Res 56(4):362-367

Soares FC, Lima RA, Salvador DM et al (2020) Reciprocal longitudinal relationship between dental fear and oral health in schoolchildren. Int J Paediatr Dent 30:286-292

Ten Berge M, Veerkamp JS, Hoogstraten J, Prins PJ (2001) Parental beliefs on the origins of child dental fear in The Netherlands. J Dent Child 68(1):51-54

Venham L, Bengston D, Cipes M (1977) Children's response to sequential dental visits. J Dent Res 56:454-459

\section{Publisher's Note}

Springer Nature remains neutral with regard to jurisdictional claims in published maps and institutional affiliations. 